\title{
THE SAN ANTONIO, CHILE, EARTHQUAKE OF 3 MARCH 1985
}

\author{
Ian N. Connor*
}

\section{$\underline{\text { ABSTRACT }}$}

This paper consists of the author's observations on the damage caused by the earthquake of 3 March 1985, centred near San Antonio, Chile. The damage was inspected approximately four weeks after the earthquake. At that time the overall cost of the damage caused by the earthquake was estimated at NZ\$1,750 million.

\section{INTRODUCTION**}

The main earthquake occurred at 1947 hours local time on 3 March 1985.

Seismological records indicate that the earthquake actually consisted of two main shocks occurring within eleven seconds of each other. The first was of surface wave magnitude 5.2 on the Richter scale and was centred offshore of the town of Algarrobo. The second was of magnitude 7.8 and was centred offshore of the city of San Antonio approximately 40 kilometres south of Algarrobo. Both epicentres were at 33 kilometres depth.

The shocks combined to give violent shaking, reported for two minutes duration and were unable to be felt separately.

Although the effects were felt over a 1500 kilometre length of Chile, surface damage was minimal even in the immediate vicinity of San Antonio. There the major surface damage was confined to a subsidence on a large port reclamation, minor landslides at road cuttings and swamping where masonry retaining walls collapsed.

In the major earthquake(s) of 3 March approximately 170 people were killed, 2000 to 3000 injured and 200,000 made homeless. Casualty figures would have been much higher had the earthquake occurred during a weekday rather than at 8.30 on a Sunday evening. Some 200 schools were severely damaged and had to be closed along with numerous industrial structures.

* Senior Engineer, Morrison Cooper

\& Partners, Christchurch.

** Full statistics for the earthquake are being sought from Chile and from the US Geological Survey.
Approximately 500 recorded aftershocks occurred in the month following the main shock. Some of these had a Richter magnitude of 4.5. The author experienced one of MM5 intensity on 8 April in which the shaking of tall buildings and the rolling motion of streets was clearly visible. As of 8 April 1985 the damage was astimated at NZ\$1,750 million but the final cost was expected to be three to four times that amount.

\section{GENERAL OBSERVATIONS}

Overall damage in the metropolitan area of Santiago and region surrounding San Antonio-Santiago from Concon $(135$ kilometres north) to Carico (195 kilometres south) indicated that the earthquake had an intensity of MM7 to 8. Many residential, small commercial and industrial buildings suffered major structural damage and some large buildings, generally ten to fifteen years old or older, were badly damaged. Generally, new structures, both large and small, suffered very little, if any damage.

Residential areas suffered very badly. Most homes, particularly outside the wealthier areas of Santiago, are constructed from adobe bricks and mortar and as expected, these buildings suffered badly. Fallen parapets and collapsed walls resulted from inadequately tied roof structures and adjoining walls. The author visited the much publicised villages of Talagante and Melipilla and the port city of San Antonio, as well as the suburbs of Santiago, and in all areas 70-80 percent of adobe buildings suffered some damage ranging from cracks at wall junctions and parapets to complete collapse of walls and roof. The extent of damage in most cases was hard to assess accurately as much demolition, and often reconstruction in the same materials, had taken place in the month after the earthquake. 


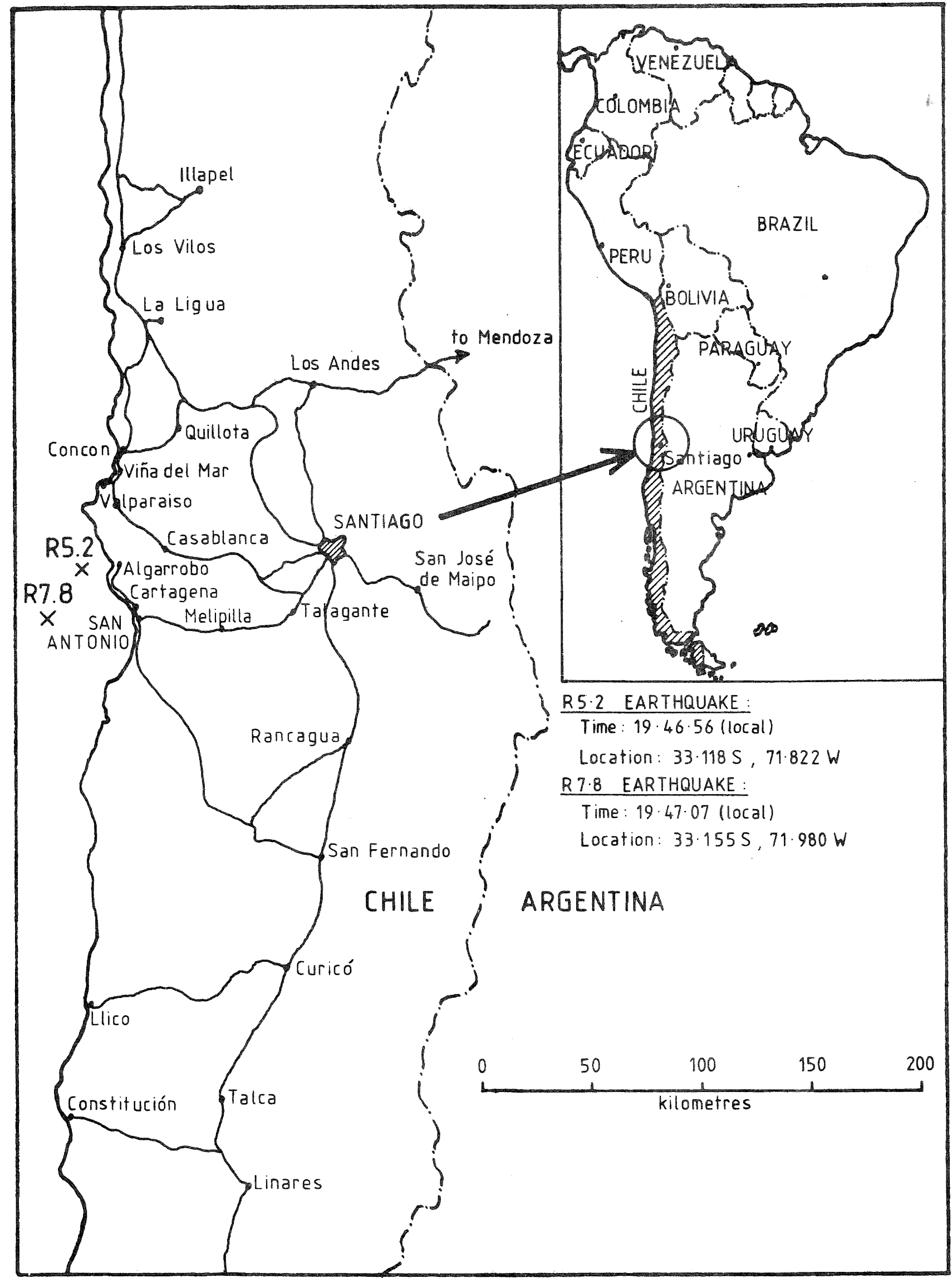

Figure 1. Area affected by the San Antonio Earthquake, Chile, 3rd March 1985. (see inset for location). 
Reportedly almost all villages around the San Antonio-Santiago region suffered the same high level of destruction, mainly because of the predominant, poor earthquake resistant adobe construction.

Surface damage in general was not as severe as one would expect from the level of building damage. Many mountain roads (the main Andes range is less than 150 kilometres from San Antonio) suffered from rock falls. Apart from this, the only other surface damage the author was able to note was landslides resulting from masonry retaining wall failures and large-scale subsidence in the reclaimed areas of the port at San Antonio. The damage reduced the port's operating capacity by more than 50 percent. The subsidence appeared to be largely due to liquefaction of the failure of wharf foundations and retaining walls.

General structural damage to many commercial and industrial buildings was inspected. Most buildings in this region of Chile are constructed from in-situ reinforced concrete or masonry and there are very few structures of steel or timber. The main reasons for this are the local availability of materials for concrete and masonry, the low cost of labour, the high cost of imported steel from overseas and the high cost of timber from the south of the country.

Most damage occurred to buildings of 15 years or older due in the main to faulty detailing. Judging from the typical failure of shear panels, shear failure at column/slab joints and similar damage the faults could probably be put down to a lack of understanding at the time of ductility requirements and the differing behaviour of structural elements. More modern buildings behaved very well with hardly even a broken window in most buildings. One main road bridge south of San Antonio collapsed during the earthquake but the author was unable to visit it.

Most of the medium-rise, heavy, reinforced concrete buildings in the centre of Santiago dating from the 1930s to $1950 \mathrm{~s}$ also showed very little damage. Many large masonry structures constructed in earlier years, typical of the sort of masonry buildings found in the centre of New Zealand cities, showed severe damage at corners, parapets and at large wall openings.

\section{INDIVIDUAL BUILDINGS} 1.irca $\frac{\text { Block } 72 \text { - Villa Olimpica }}{1962 . \text { A five-storey apartment }}$ block with a combination frame/shear wall structure in which end wall columns failed completely at their connection to the shear wall causing complete collapse of one bay of all floors. Block 72 is part of a large housing estate of similar structures, many of which showed some damage but which was generally confined to infill block walls on higher floors and roof mounted water tanks in other blocks.

Failure appears to have been due to lack of capacity at the column/shear wall connection on the west end wall of the block. Column ties at this highly stressed joint are too widely spaced, too small and inadequately anchored into the core to provide either sufficient shear capacity or confinement to the main column bars and the columns appear to have suffered a shear-compression failure.

Both the failed columns showed extensive fine cracking in both main faces. Although a general pattern was hard to see, it did appear that the cracks were inclined and were shear cracks. There did not appear to be any disturbance of the ground at the base of the columns indicating that the columns failed in shear and compression long before flexural capacity was reached.

From the overall orientation of the building (see sketch) the presence of cracks at the connection of the bridges to the adjacent block (see photograph $3)$ and the apparent east-west direction of the general ground motion, it seems that torsionally induced shear loading of the end wall initiated the failure. The relatively stiff stairwell structure at the east end of the block and the eccentric effect of the bridge restraints would have accentuated the torsional effect of basic eccentricity of the structure.

Some cracking of the east-west walls of the stairwell was visible, but only along the horizontal lines of construction joints and there was no apparent spalling at wall extremeties or floor connections. The sliding joints at the east end of the floors where they connected to the adjacent east-west block had moved - by approximately $100 \mathrm{~mm}$ at the roof slab connection - although it is difficult to say how much of this would have been due to the "dragging" effect of the collapsed slabs as they fell.

The connection of the bridges to the adjacent north-south block would have been expected to have a sliding joint at the end of their connection but this had not been constructed as such, and spalling on the bridge support beam (see photograph 3) confirms this. The internal columns of the adjacent north-south block were partially constructed of masonry and suffered severe damage, indicating significant deformation of this block, also five storeys.

Similar lack of adequate column ties is evident in the photo showing damage to the base of the south column in the second row from the west face. The failure of this column appeared to have been in compression, not in shearcompression, and possibly occurred at the moment when the west end columns failed and the end wall and upper floors collapsed, momentarily transferring excessive axial load on to these columns. No clearly identifiable shear cracks 


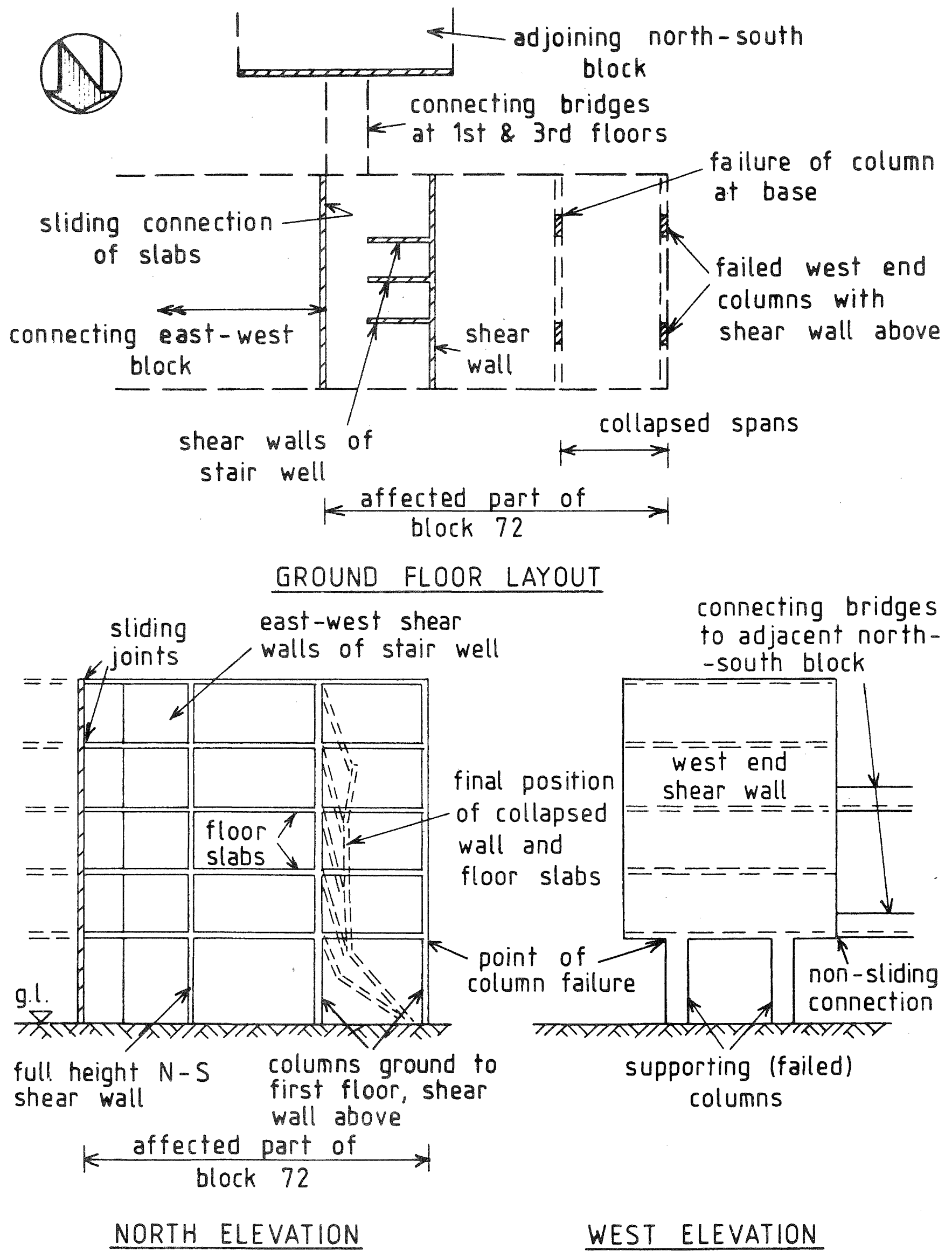

Figure 2. Villa Olimpica - Block 72 Layout. 
(sə6p!ıq 6u!noouนos ol surea yoddns 10 spue je 6ulleds

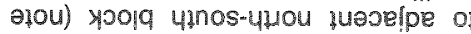
suolloeuuos ә6p!nq-1seว ә4! te yoolq

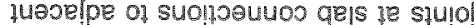
6u!p!|s bu!mous yงol9 10 ap!s yinos

'siem jeaus pue

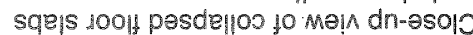

$\rightarrow 0104 d$

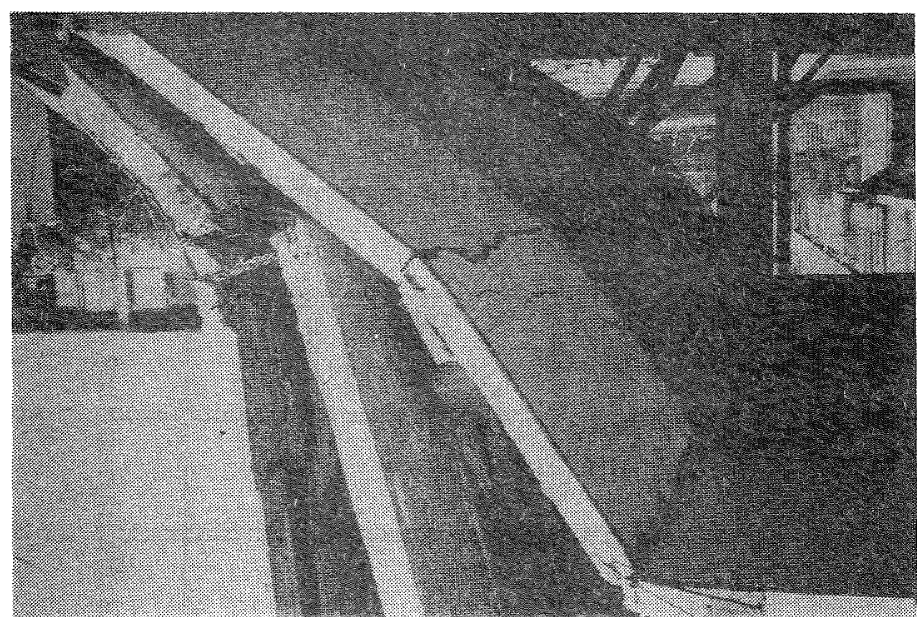

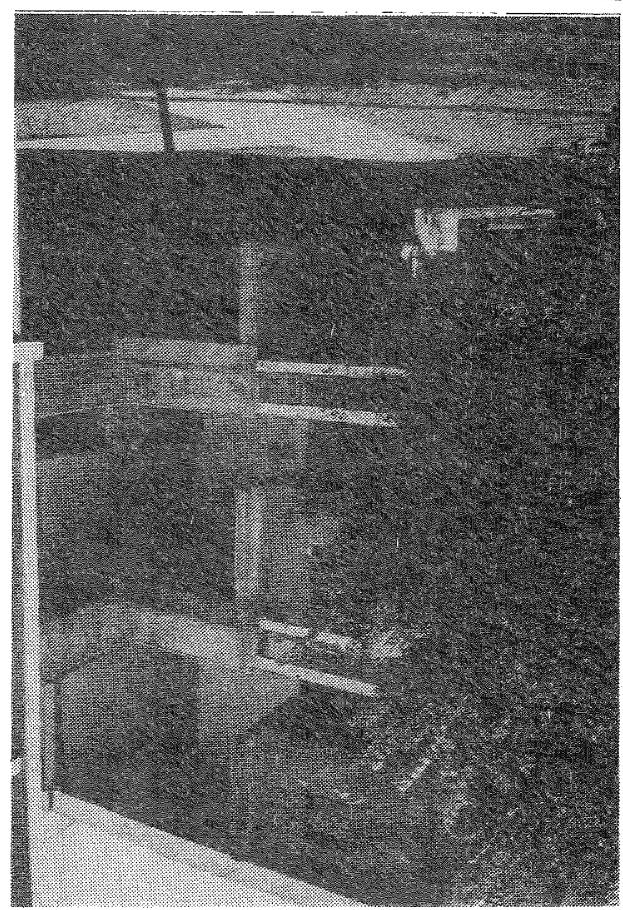

\section{¿L}

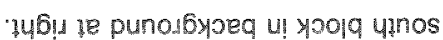
-4นоน 6u!u!

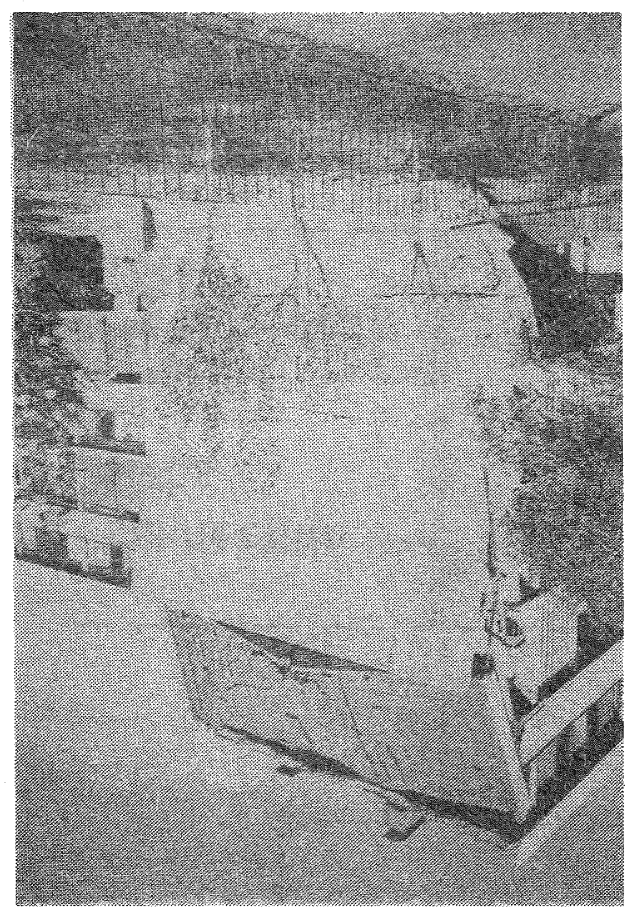

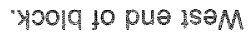

it oloud

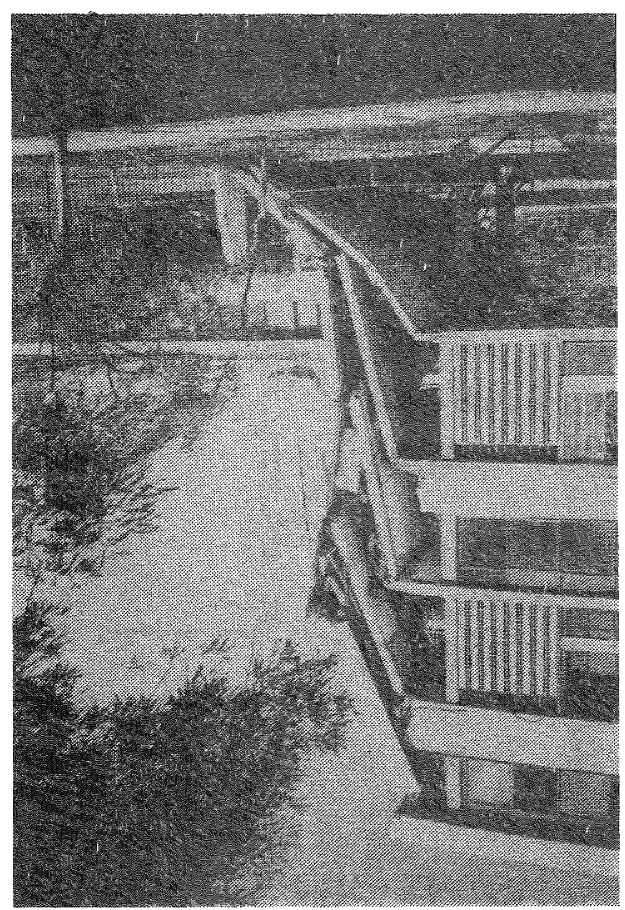




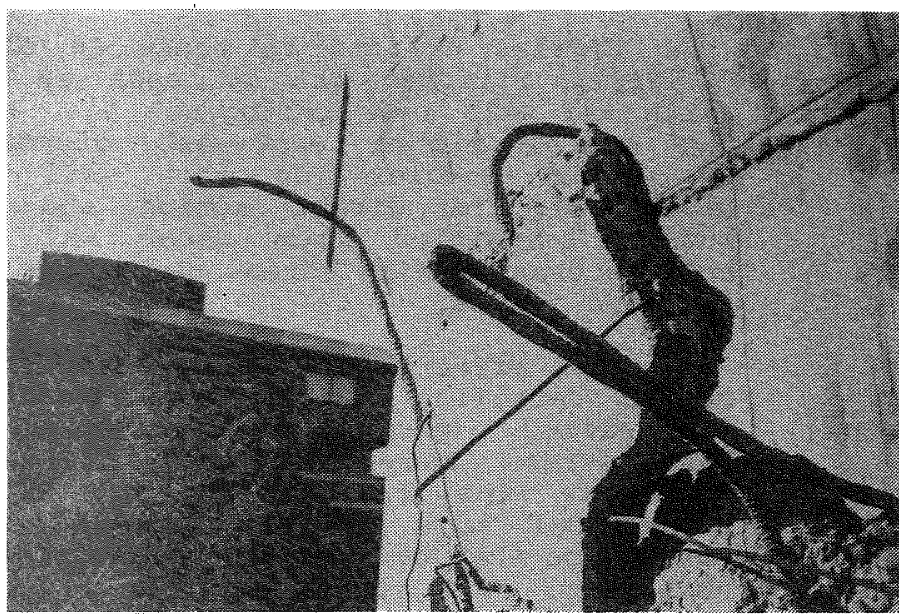

Photo 5. Close-up view of shattered top of failed column.

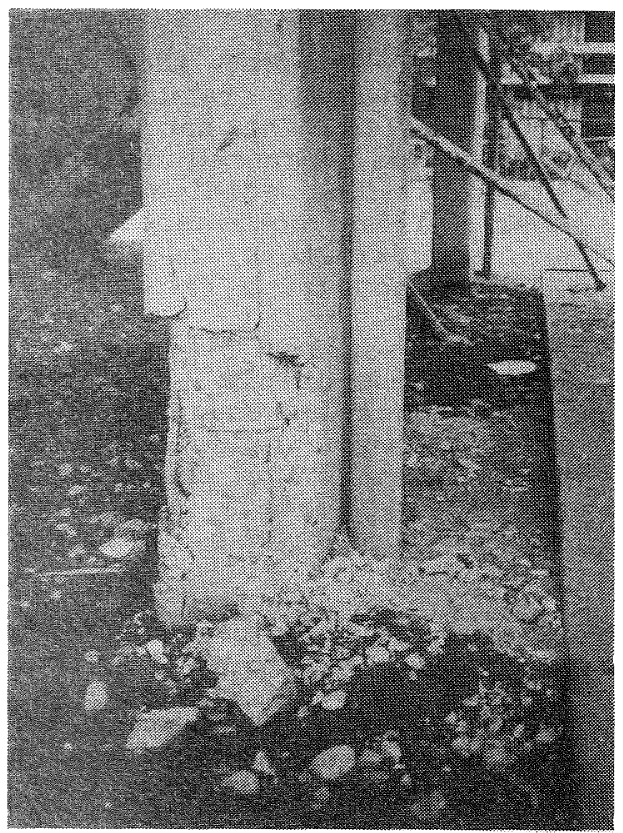

Photo 7.

Failure at base of south column second row from west.

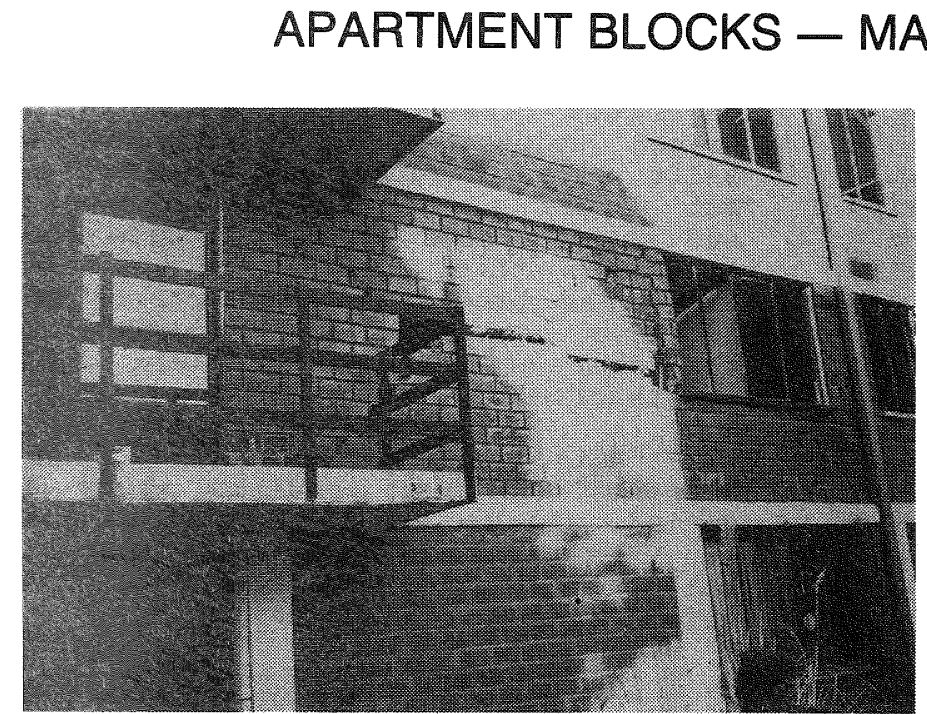

Photo 9. Shear cracks in unconfined first floor wall panel.

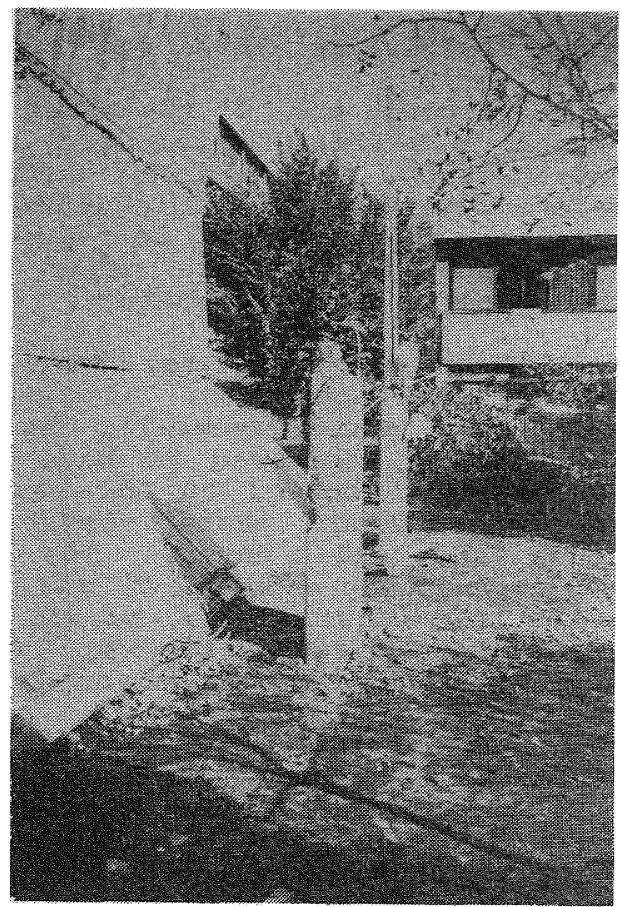

Photo 6. Failed west end column.

\section{VILLA OLIMPICA - BLOCK 72}
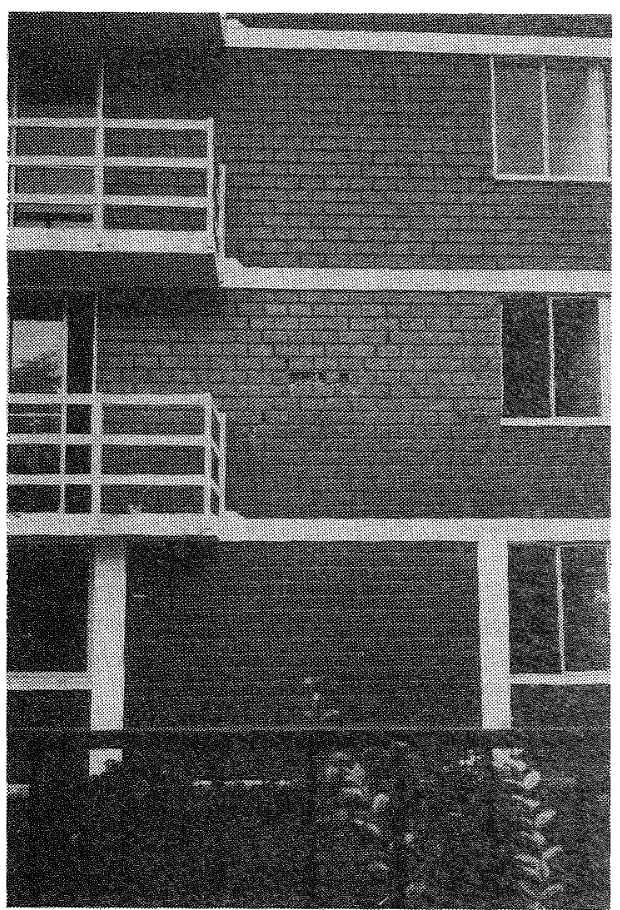

Photo 8. Shear cracks in unconfined first floor wall panel. 
were visible on this row of columns.

Although most of the other apartment blocks in Villa Olimpica were of similar construction, they had not suffered such severe damage. The rigid bridge connection to the adjacent north-south block appears to have had a major effect on the response of the structure.

Poor materials may have had some effect but aggregate, although larger size than would generally be used in New Zealand, appeared to have been reasonably well bonded. to the cement paste and the cement paste itself appeared sound and well cured. The materials and workmanship on block 72 did not appear to be particularly poor, or any different from the adjacent blocks. Cores had been cut from concrete slabs for testing purposes.

Typical damage noted on many of the other blocks included damage to perforated concrete block infill panels on third and fourth floors. These had no reinforcement because of the free air flow type of block and hence had little integrity in seismic motion. Also, many roof mounted concrete and masonry water tanks showed spalling damage at their bases and wall corners. Shear walls along the principal side walls of the blocks showed diagonal cracks originating at the corners of openings indicating insufficient trimming reinforcement.

2. Apartment Blocks - Macul - built about 1979. Four storey brick apartment blocks with in-situ concrete slabs and reinforced concrete frames to the first storeys only. Failure occurred in the load bearing brick walls between the first and second floors, and because of this all floors above are now very unstable even under gravity loads.

The damaged brick panels show predictable diagonal shear cracks in both directions from lateral load reversals. The cracking has occurred at the first floor rather than the ground floor where the concrete frames have provided confinement to the brick walls. The first floor walls are completely unconfined by either column or reinforcement. The walls do have some reinforcement but this is nominal and totally inadequate to prevent the cracks opening.

The effect of inadequate tying of parapets was also illustrated on these blocks. The parapet tie beam, which is obviously adequately reinforced in itself, was completely cut at each end where it tied back to the adjacent walls by rainwater gutters, leaving only the unreinforced bricks as support.

3. Apartment Blocks - Villa Portales - built about 1970. Seven storey apartment blocks with combination frame/shear wall structures in which damage occurred at shear wall edges, shear wall/column connections, internal walls and water tanks. All blocks on this large housing estate suffered similar damage, although of varying severity.
Similar effects to those in block 72 Villa Olimpica can be seen on the north end wall (see photograph 9). With the characteristic east-west direction of ground acceleration this wall was effectively in direct action and the sudden transition from shear wall to columns created high stress concentrations at these joints.

The effects of floor main steel cutoff detailing and inadequate column tie sizing, spacing and anchorage in high stress zones are evident. Main bars have laps, cutoffs and hooks within a critical zone and have created such congestion that bars have had insufficient anchorage. Tie steel, as well as being spaced widely, has not been anchored into the column core, possibly because main bar congestion has prevented this.

Further photographs show similar inadequate confinement reinforcing at interior shear walls. At bar hook locations spalling has occurred (see photograph 12) and at the critical end zone of one shear wall no confinement is provided over approximately one metre of bar length (see photograph 13).

Another photograph (14) shows problems from incompatible deformations where stair flights and supporting beams connect with the shear walls. The photograph shows propagation of shear cracking from the punching damage resulting at the rigid beam connections to the shear wall.

Many internal non-structural walls in the blocks were of thin, lightly reinforced concrete and, because of the lask of structural separation from the floors above, were very badly damaged (see photograph 15).

On almost all the apartment blocks in Villa Portales, roof mounted water tanks suffered severe damage. Lack of allowance for torsional effects on full tanks in support design appeared to be the main problem. Tanks were supported on either crossed shear walls, or cross braced columns. The supporting shear walls were integral with support beams but formed a step at their connection and shear forces appear to have concentrated at this step to induce failure. The cross braced column supports appear to have been totally inadequate under torsional effects and complete collapse has resulted.

Although the actual design of supports for roof mounted water tanks varied widely in Santiago, damage to many was noted, especially on higher buildings, indicating the amplification effect on such structures.

4. Older Masonry Structures - Many older buildings in santiago are of massive unreinforced masonry and date from around the turn of the century. Similar buildings can be found in the centre of many New Zealand cities. Such buildings could be expected to sustain similar damage even in a moderate earthquake. 


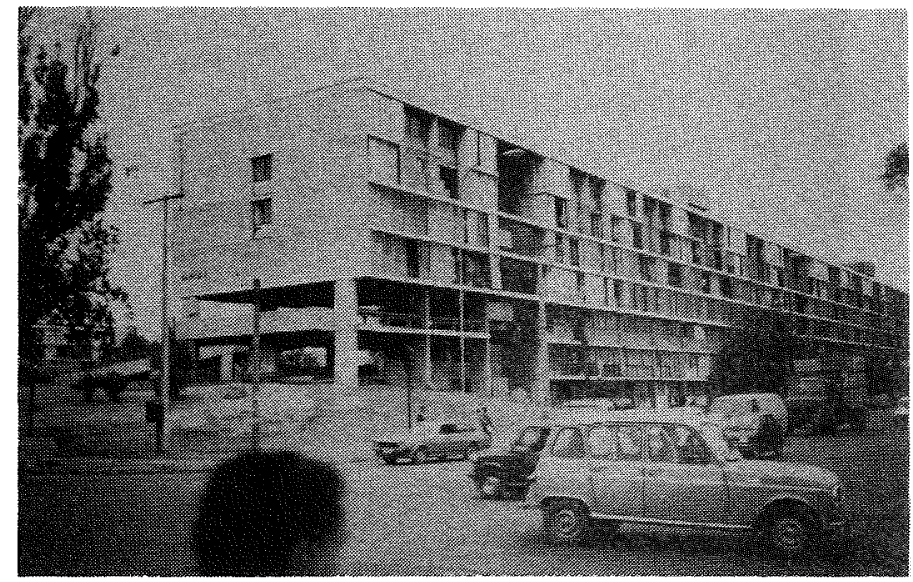

\section{VILLA PORTALES}

Photo 10. North end wall showing shear wall transition to columns.

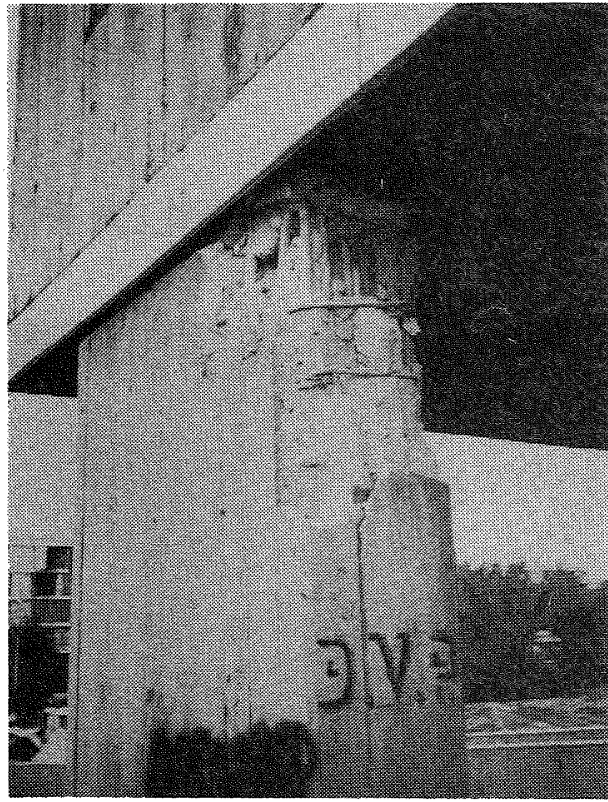

Photo 11. Left-hand (east) column/wall joint.

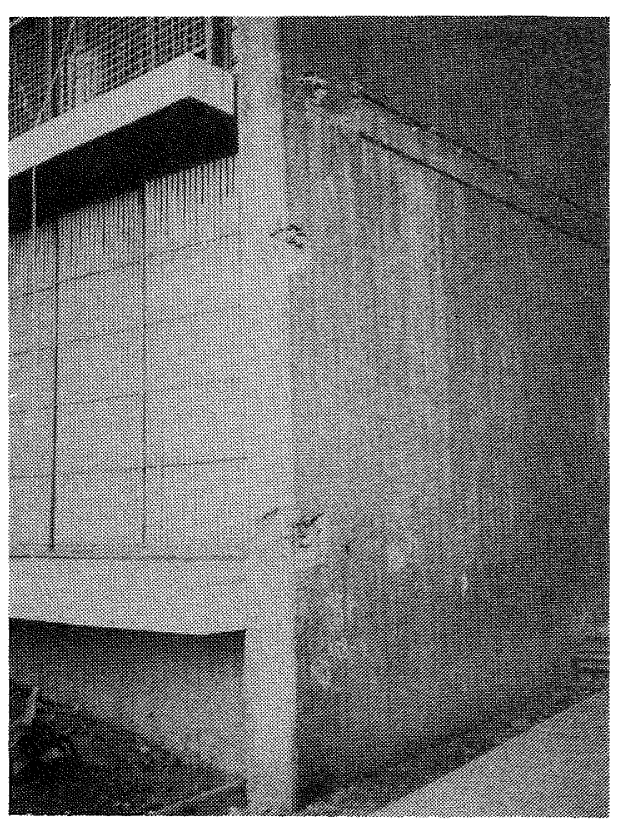

Photo 13. Spalling at slab connection to shear wall and at main bar hooks at edge of east-west shear wall.

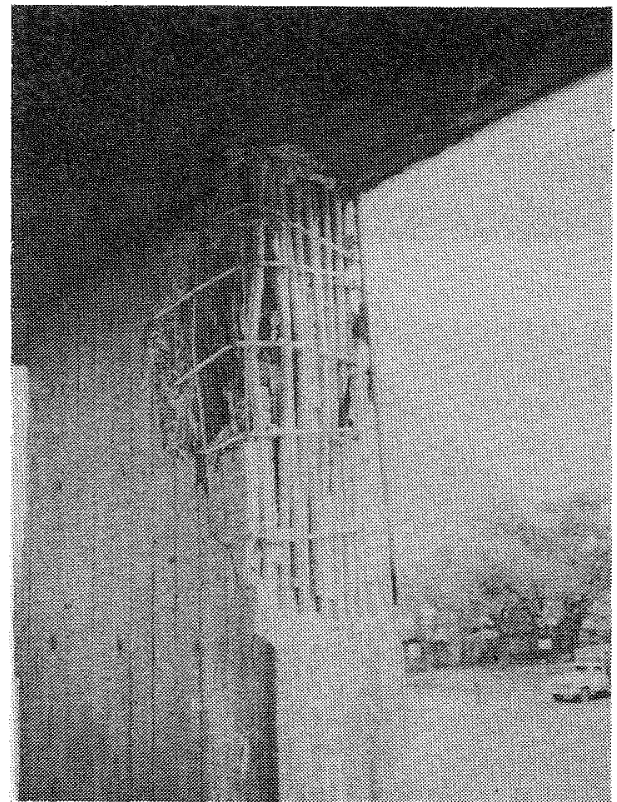

Photo 12. Right-hand (west) column/wall joint.

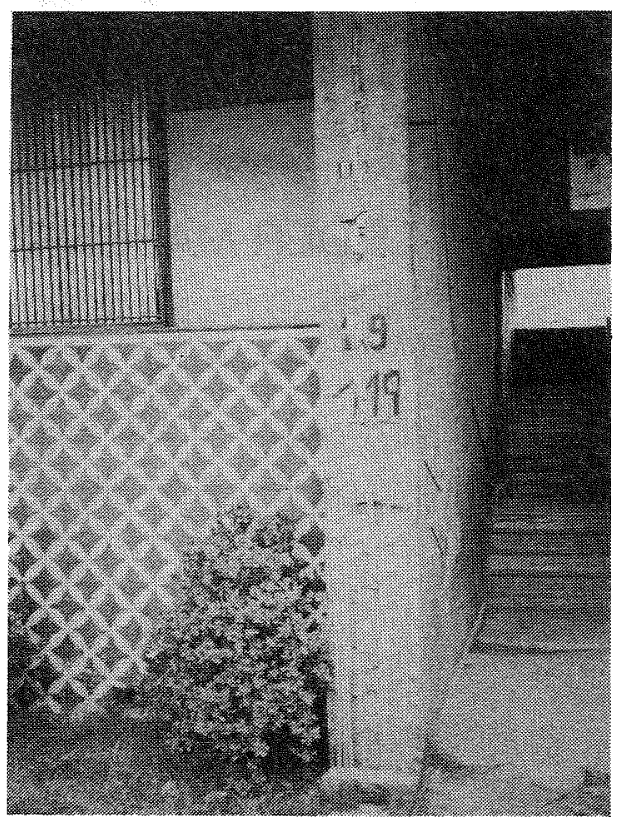

Photo 14. Spalling at unconfined main bars at base of east-west shear wall. 
136

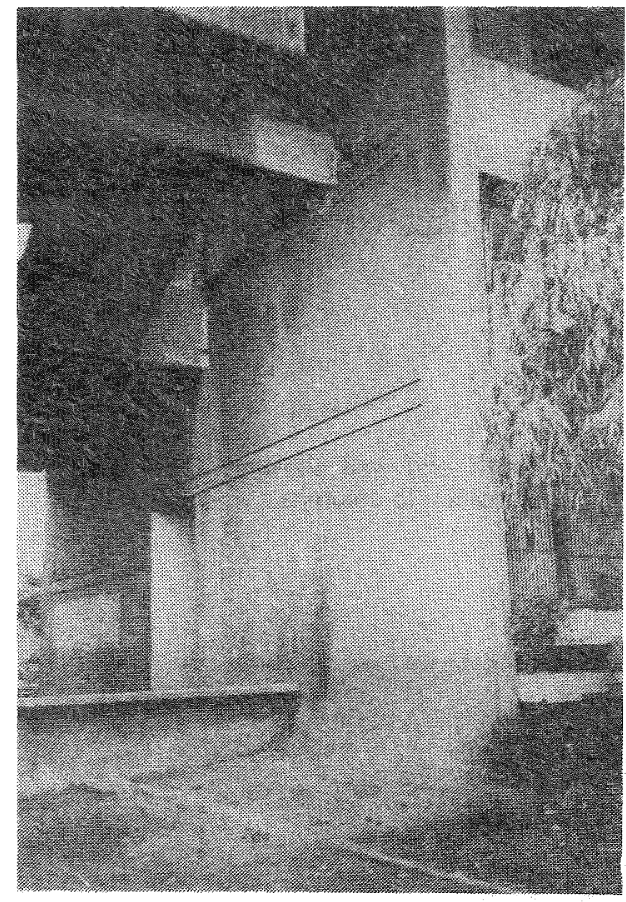

Punched holes and connecting

cracks in shear wall at stair connection to east-west shear wall.

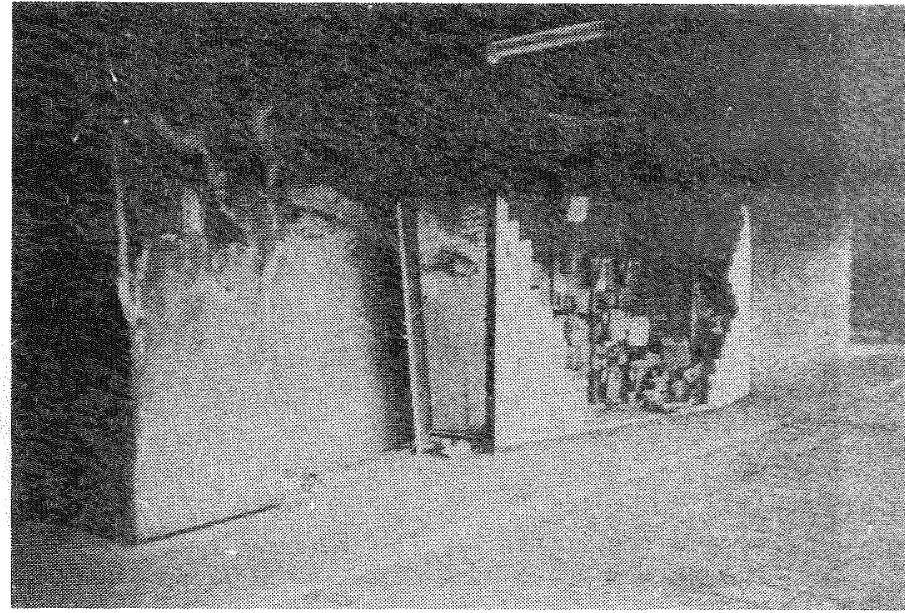

Photo 16. Typical damage to non-structural internal partition.

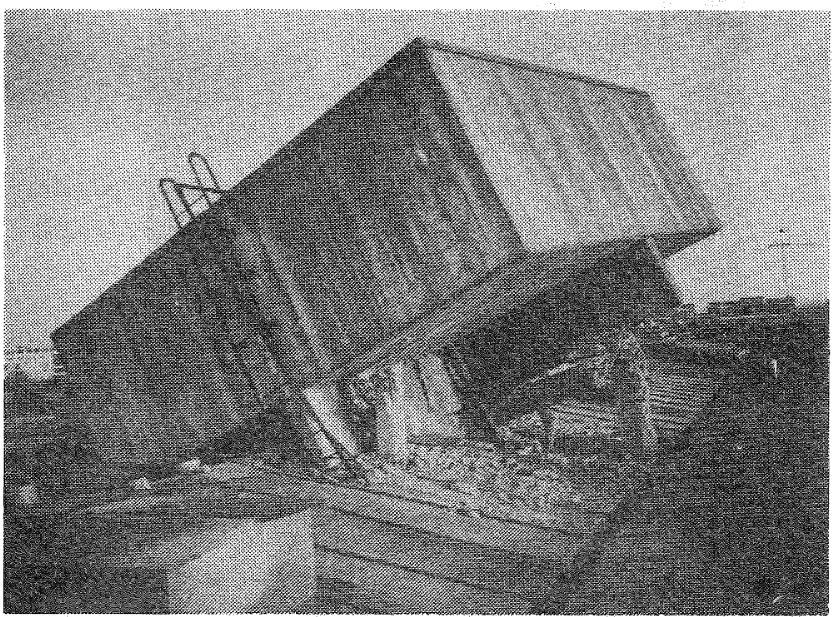

Photo 17. Toppled water tank supported on cross-braced columns.

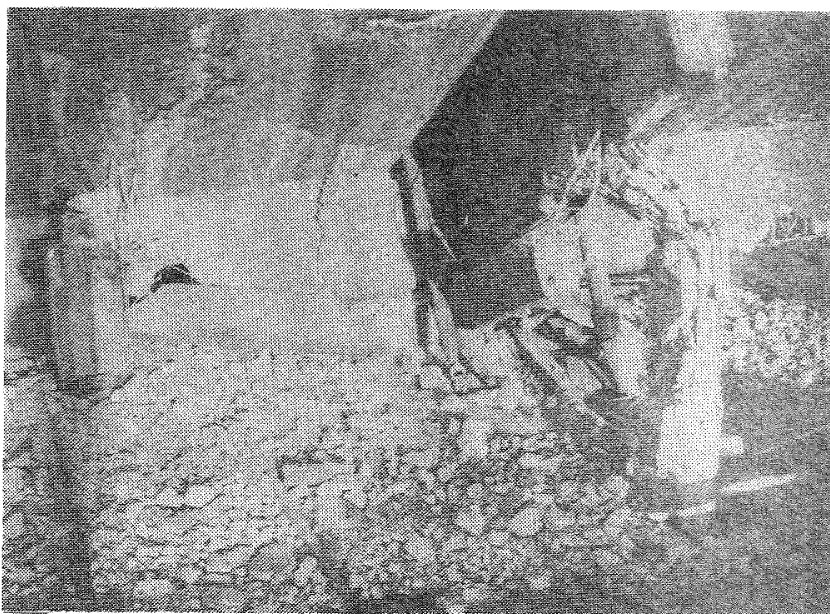

Photo 18. Close-up view of failed supports.

\section{VILLA PORTALES}


Inadequate tie-back of masonry walls at the roof and floors on the main City council headquarters in the centre of Santiago resulted in serious cracking, particularly at the corners of the building. As would be expected, cracking was concentrated at openings in the walls. Similar cracking occurred in the clock tower which was seriously damaged.

Damage at the corner of an old masonry building and cracking at openings is evident in the photograph of a high stud commercial building located in the same square as the City Council headquarters. Imminent collapse of the heavy, untied parapet is also visible in this photograph.

Dislocation of inadequately tied, heavy dormer windows and similar cracking at the corners of the building are evident in the photograph of an old commercial building on the same block as the City Council headquarters.

5. Smaller Masonry/Concrete Structures With the main earthquake being centred offshore from San Antonio, many buildings in this area suffered damage. In general, most newer buildings survived very well but many structures, 30 years and older, suffered severe damage.

In general, damage was exactly as could be expected and occurred in unreinforced, or inadequately reinforced panels or walls supporting heavy roofs and floors. Damage occurred to infill walls where they were either not structurally separated from a framed structure, or inadequately reinforced when they were incorporated in the structure; and where walls and parapets were not designed or tied back to resist out-of-plane earthquake loadings.

6. Reclamation Failure

At San Antonio, the second largest port in Chile, extensive subsidence of a largescale port reclamation dating from about 1971 destroyed a solid wharf facility, and caused the complete collapse of 30 metres of an open piled wharf. In addition, major damage occurred to remaining structures at the port.

As expected, buildings on the reclamation suffered badly from the subsidence although a large three-pinned steel arch warehouse structure remained in excellent structural condition in spite of bad damage from toppling wharf cranes and extensive foundation movement.

A small tank farm for storage of byproducts from a fish processing plant, situated on the same reclamation, showed pumping of the tank foundations. The steel tanks themselves and concrete foundations remained basically undamaged, although connecting pipework was ruptured. The tanks, approximately 7 metres in diameter and 7 metres high, had been deformed out-of-vertical by up to $300 \mathrm{~mm}$. Although no base restraint was provided to any of the tanks, translation was less than $10 \mathrm{~mm}$ in the worst case. had been done when the author visited it. Liquefaction appeared to be the major cause of the failure, as indicated by the pumping of the tank foundation. The reclamation behind the failed solid wharf appeared to be variabie in character with clay, concrete rubble and even some general building rubbish being evident. This, plus water being present in the backfill, may have contributed to the wharf failure.

\section{CONCLUSIONS}

Although the author has no information on the structural design codes used in Chile, the almost complete absence of damage to modern buildings, both low and high-rise, indicates that modern earthquake engineering practice is providing adequate protection against damage in moderate earthquakes.

From the damaged buildings inspected it appears that buildings ten to fifteen years and older (possibly corresponding to pre-1965 in New Zealand) could have some problems in a moderate earthquake. This is particularly so where structures with differing response chacteristics to seismic loading are rigidly connected together into one structure.

The older, unreinforced masonry buildings, even where good quality construction has been used, are particularly susceptible to earthquake damage. Unless walls are tied back and incorporated with some adequate lateral load resisting system, severe cracking at corners and large wall openings can be expected in a moderate earthquake.

Adobe buildings, corresponding to poor quality brick buildings in New Zealand, show almost no integrity in earthquakes and are a major danger to life.

Probably the major and lasting impression the author gained from viewing the earthquake damage was the need for careful attention to detail in design and construction. Much of the damage observed had occurred where bad detailing, or poor site supervision, had resulted in inadequacies at locations of high ductile demand in structures.

\section{ACKNOWLEDGEMENTS}

The author gratefully acknowledges the assistance of Mr Richard Mann of the New Zealand Embassy in Santiago, and Sr Fruilon of the Colegio de Ingenieros in Santiago for invaluable introductions and directions. 


\section{PORT OF SAN ANTONIO}

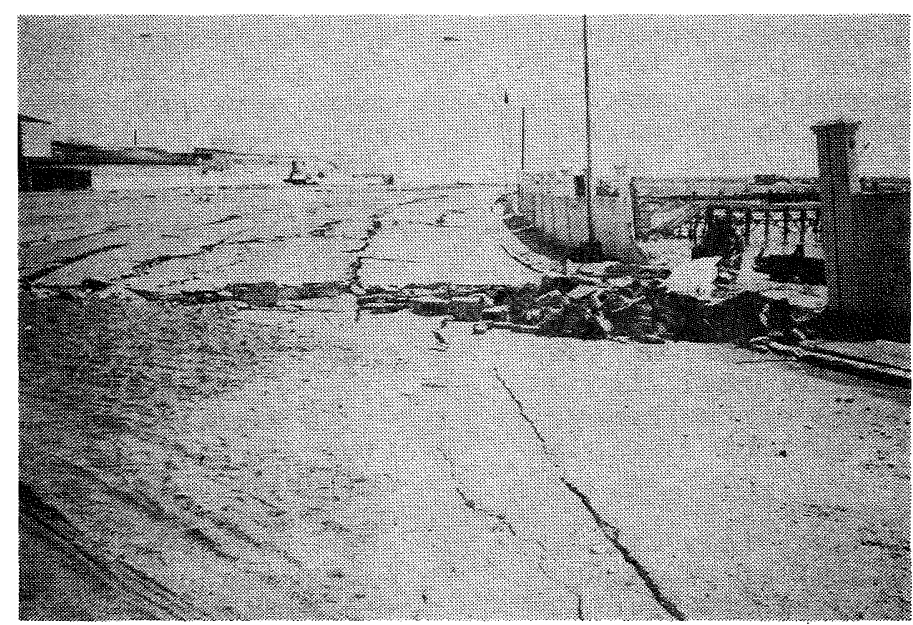

Photo 21. Subsidence in port reclamation. Collapse of end of piertype wharf and subsidence of foundations.

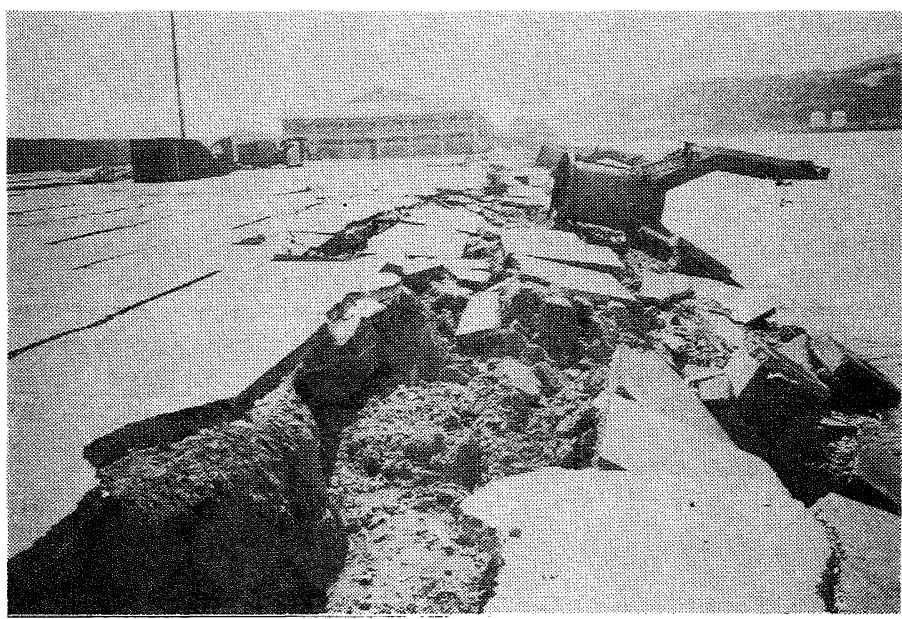

Photo 22. Subsidence of reclamation and complete collapse of retaining wall wharf leading to crane toppling.

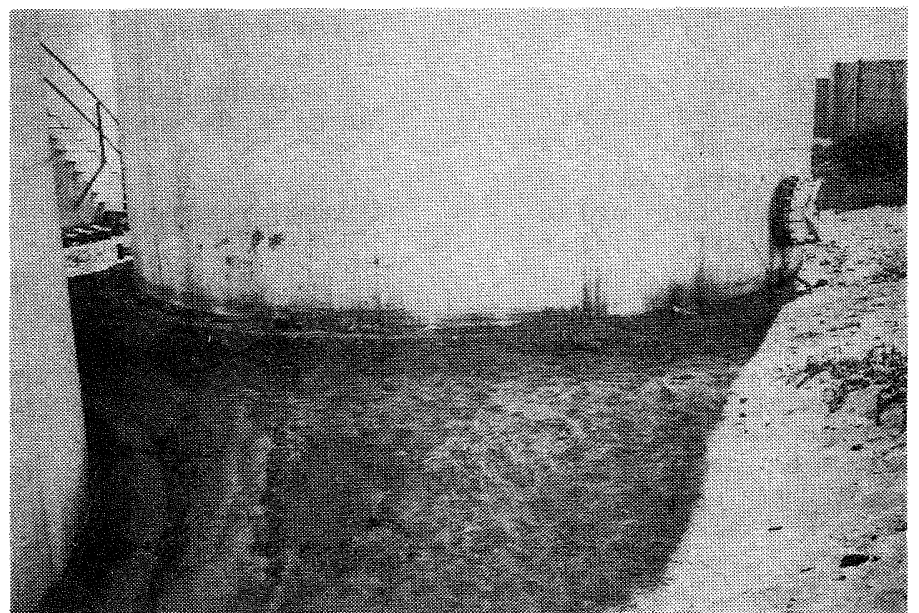

Photo 23. Evidence of pumping of tank foundations on reclamation. 